\title{
Assessing the Impact of Youth Empowerment on Bringing Social Change in Punjab
}

\author{
Muneeba Arshad \\ Department of Sociology, GC University, Faisalabad, Pakistan
}

Nazia Malik

Department of Sociology, GC University, Faisalabad, Pakistan

Haq Nawaz

Department of Sociology, GC University, Faisalabad, Pakistan

Zeeshan Farid

Department of Agronomy, University of Agriculture Faisalabad, Pakistan

\section{Doi:10.5901/ajis.2014.v3n4p331}

\section{Abstract}

The objective of this study is to highlight the importance and role of 'Youth' in Pakistan. In Pakistan, sixty-three percent of population is under the age of twenty five; this section of population is 'Youth' of country. Youth are a major driving force in the progress of any country. In a country where youth forms the majority of society, power and authority must be in the hand of youth. Empowerment of Youth is often termed as a path to intergenerational peace, civic engagement and democratic stability. Today many local, international agencies and nonprofit organizations are providing programs focused on youth empowerment. Present study focused to assess the impact of youth empowerment on bringing social change in Punjab. Present study was conducted in Punjab city. Three government universities i.e. Punjab University Lahore, Gujrat University and University of Agriculture, Faisalabad were selected randomly. Proportional sample sizes of 200 students were selected randomly. Welldesigned interviews were used to collect data. Descriptive and inferential statistical techniques were used for analysis. It was found that majority of the respondents had knowledge about socio-economic, political, educational and social issues policies empower youth. It was concluded that majority (95\%) of the respondents had thinking that that the development of specific communicational skills empower youth. Large majorities (74\%) of the respondents were satisfied with the policy of promoting technical education. It was found that significant association between gender, age, education, income, marital status and satisfaction with the policies regarding women empowerment with their perception about the impact of youth empowerment on bringing social change. Strong political will is required in order to empower women. To achieve this, vital role can be played by women politicians and activists by highlighting women's' issues at various forums. Moreover, priority should be given to solve these issues by the government.

Keywords: Youth empowerment, social change, intergenerational peace, and Punjab

\section{Introduction}

The youth play pivotal role in the development of the society and strongest agent of social change. The youth are a critical force in the development of any society; they are backbone of nation and can change the future of the society with their well-being and courageous behavior. Pakistan has a large population that can be categorized as falling within definition of youth. An estimated 103 million Pakistanis, or $63 \%$ of the population, fall under the age of 25 years. However, as a result of endemic poverty, the majority of youth in Pakistan do not have the opportunity to experience a childhood. Youth literacy rate Youth Literacy Rate (age 15/24) is estimated to be $53 \%$. Female youth literacy (age 15-24) conforming to the wider pattern in Pakistan, is even lower at $42.0 \%$. Young people engaged in practical and deliberate way of effecting social change. Over the last 64 years of independence, Pakistan has duly witnessed the results of young blood boiling within its youth. With worth appreciating youngsters who have succeeded in taking Pakistan to a newer level altogether, victories were made.

The largest waves of young people in history are into adulthood today. Young people have the potential and 
willingness to bring about momentous change, therefore they must be provided with opportunities to play a significant role for creating better lives for themselves, their communities and society as a whole. "Pakistan is proud of its youth, particularly the students who have always been in the forefront in the hour of trial and need. You are the nation-builders of tomorrow and you must fully equip yourself with discipline, education, and training for the arduous task lying ahead of you. You should realize the magnitude of your responsibility and be ready to bear it."(31st Oct. 1947). "Youth is the stage of constructing the Self-concept. The self-concept of youth is influenced by several variables such as peers, lifestyle, gender and culture. It is this time of a person's life which they make choices which will affect their future." This world demands the qualities of youth not a time of life but a state of mind, a temper of the will, a quality of imagination, a predominance of courage over timidity, of the appetite for adventure over the life of ease.(Robert Kennedy)

Social determinants, including socioeconomic, cultural, and environmental conditions, are the root cause of poor health and associated inequities between and among various racial, ethnic, or other demographic groups, and countries (Marmot, 2005). To effectively improve health status, we must modify or change social determinants. To do so will require a transformation of policies, rules, regulations, and legislation among various sectors, including, but not limited to public health, business, industry, and medicine. The change needed to affect social determinants is not the responsibility alone of policy makers and institutions. A shift in people's beliefs and how they think about issues, and subsequent individual advocacy efforts can support social change (Mankoff et al. 2007).

Youth Empowerment was developed by the Commonwealth Secretariat, working closely with Ministers of Youth and young people themselves. It encourages youth mainstreaming and contains thirteen action points for governments. The first of these is: "Develop and implement measures to promote the economic enfranchisement of young people" through a range of measures ranging from micro-credit and entrepreneurship education through to reviewing macroeconomic planning and trade regimes and how they affect young people. Other action points address gender equality, HIVIAIDS, education, the environment, youth participation in decision-making, and democracy and human rights.

Empowerment is essentially a liberty in political, economic, and social sector and having awareness on different issues especially on their rights. The World Bank also defines empowerment as "the process of increasing capacity of individual or groups to make more choices and to transform these choices into desired actions and outcomes" (WHO, 2006).

\section{Materials and Methods}

It gives the study design, selection criteria for respondents, sampling procedures, sample size, selection and different statistical techniques used for data analysis, such as Uni-variate analysis and Bi-variate analysis. Therefore, the main objective of this chapter is to explain various tools and techniques employed for the data collection, analysis and interpretation of the data. They are discussed at length in this chapter. The universe of this study is province Punjab. Present study was conducted in province Punjab. Three government universities i.e. Punjab University Lahore, Gujrat University and University of Agriculture, Faisalabad were selected randomly. A proportional sample size of 200 students was selected randomly.

\begin{tabular}{|l|c|c|c|}
\hline \multicolumn{1}{|c|}{ University Name } & Total students & Proportion (\%) & Selection of respondents \\
\hline Punjab University, Lahore & 30000 & 55 & 110 \\
\hline Univ. of Agri., Faisalabad & 15000 & 28 & 56 \\
\hline University of Gujrat & 9000 & 17 & 34 \\
\hline Total & 54000 & 100 & 200 \\
\hline
\end{tabular}

In order to design the questionnaire the two basic principles were kept in mind. First, questions were made by keeping the viewpoint of respondents so that chance of confusion eliminated. Second, during construction of questionnaire some biases were avoided such as jargon, slang, ambiguity, confusion, emotional language, prestige biases, double barreled questions, threatening questions, false premises and double negatives.

\section{Result and Discussion}

Bivariate analysis showing relationship among various socio-economic characteristics of the respondents and their opinion about their perception about the impact of youth empowerment on bringing social change. In this study mostly the bivariate and multivariate statistics were used. The results are as under: 
Testing Of Hypotheses

Hypothesis 1: There is an association between gender and their perception about the impact of youth empowerment on bringing social change

Table 1: Association between gender and their perception about the impact of youth empowerment on bringing social change

\begin{tabular}{|c|c|c|c|c|}
\hline \multirow{2}{*}{ Gender } & \multicolumn{3}{|c|}{ Impact of youth empowerment on bringing social change } & \multirow{2}{*}{ Total } \\
\cline { 2 - 5 } & Low & Medium & High & \\
\hline \multirow{2}{*}{ Male } & 22 & 25 & 10 & 57 \\
\cline { 2 - 5 } & $38.6 \%$ & $43.9 \%$ & $17.5 \%$ & $100.0 \%$ \\
\hline \multirow{2}{*}{ Female } & 19 & 72 & 32 & 143 \\
\cline { 2 - 5 } & $13.3 \%$ & $50.3 \%$ & $62.4 \%$ & $100.0 \%$ \\
\hline \multirow{2}{*}{ Total } & 41 & 97 & $31.0 \%$ & $100.0 \%$ \\
\cline { 2 - 5 } & $20.5 \%$ & $48.5 \%$ & & \\
\hline
\end{tabular}

Chi-square $=17.74$ d.f. $=2$ P-value $=.000^{* \star}$ Gamma $=-.488^{* *}=$ Highly significant

Table 1 presents the association between gender and their perception about the impact of youth empowerment on bringing social change. Chi-square value shows a highly-significant association between gender and their perception about the impact of youth empowerment on bringing social change. Gamma value shows a negative relationship between the variables. It means female respondents had more perception about the impact of youth empowerment on bringing social change as compared to male youth. So the hypothesis "There is an association between gender and their perception about the impact of youth empowerment on bringing social change" is accepted.

Hypothesis 2: Higher the age of the respondents, higher will be the perception about the impact of youth empowerment on bringing social change

Table 2: Association between age of the respondents and their perception about the impact of youth empowerment on bringing social change

\begin{tabular}{|c|c|c|c|c|}
\hline \multirow{2}{*}{ Age of the respondents (in years) } & \multicolumn{3}{|c|}{ Impact of youth empowerment on bringing social change } & \multirow{2}{*}{ Total } \\
\cline { 2 - 5 } & Low & Medium & High & \\
\hline \multirow{2}{*}{$19-20$} & 20 & 31 & 15 & 66 \\
\cline { 2 - 5 } & $30.3 \%$ & $47.0 \%$ & $22.7 \%$ & $100.0 \%$ \\
\hline \multirow{2}{*}{$21-22$} & 11 & 51 & 20 & 82 \\
\cline { 2 - 5 } & $13.4 \%$ & $62.2 \%$ & $24.4 \%$ & $100.0 \%$ \\
\hline \multirow{2}{*}{$23-24$} & 10 & 15 & 27 & 52 \\
\cline { 2 - 5 } & $19.2 \%$ & $28.8 \%$ & $51.9 \%$ & $100.0 \%$ \\
\hline \multirow{2}{*}{ Total } & 41 & 97 & 62 & 200 \\
\hline & $20.5 \%$ & $48.5 \%$ & $31.0 \%$ & $100.0 \%$ \\
\hline
\end{tabular}

Table 2 presents the association between age of the respondents and their perception about the impact of youth empowerment on bringing social change. Chi-square value shows a highly-significant association between age of the respondents and their perception about the impact of youth empowerment on bringing social change. Gamma value shows a strong positive relationship between the variables. It means high age youth had more perception about the impact of youth empowerment on bringing social change as compared to low age youth. So the hypothesis "Higher the age of the respondents, higher will be the perception about the impact of youth empowerment on bringing social change" is accepted.

Hypothesis 3: Higher the education of the respondents, higher will be the perception about the impact of youth empowerment on bringing social change 
Table 3: Association between education of the respondents and their perception about the impact of youth empowerment on bringing social change

\begin{tabular}{|c|c|c|c|c|}
\hline \multirow{2}{*}{ Education of the respondents } & \multicolumn{2}{|c|}{ Impact of youth empowerment on bringing social change } & \multirow{2}{*}{ Total } \\
\cline { 2 - 4 } & Low & Medium & High & \\
\hline \multirow{2}{*}{ Less than graduation } & 28 & 12 & 10 & 50 \\
\cline { 2 - 5 } & $56.0 \%$ & $24.0 \%$ & $20.0 \%$ & $100.0 \%$ \\
\hline \multirow{2}{*}{ Graduation } & 7 & 52 & 17 & 76 \\
\cline { 2 - 5 } & $9.2 \%$ & $68.4 \%$ & $22.4 \%$ & $100.0 \%$ \\
\hline \multirow{2}{*}{ Post-graduation } & 6 & 33 & 45 & 74 \\
\cline { 2 - 5 } & $8.1 \%$ & $44.6 \%$ & 62 & $100.0 \%$ \\
\hline \multirow{2}{*}{ Total } & 41 & 97 & $31.0 \%$ & $100.0 \%$ \\
\cline { 2 - 5 }
\end{tabular}

Chi-square $=63.76$

d.f. $=4$ P-value $=.000^{\star \star}$ Gamma $=.524^{\star \star}=$ Highly significant

Table 3 presents the association between education of the respondents and their perception about the impact of youth empowerment on bringing social change. Chi-square value shows a highly-significant association between education of the respondents and their perception about the impact of youth empowerment on bringing social change. Gamma value shows a strong positive relationship between the variables. It means highly qualified youth had more perception about the impact of youth empowerment on bringing social change as compared to less qualified (less than graduation). So the hypothesis "Higher the education of the respondents, higher will be the perception about the impact of youth empowerment on bringing social change" is accepted.

Hypothesis 4: Higher the monthly income of the respondents, higher will be the perception about the impact of youth empowerment on bringing social change

Table 4: Association between monthly income from all sources of the respondents and their perception about the impact of youth empowerment on bringing social change

\begin{tabular}{|c|c|c|c|c|}
\hline \multirow{2}{*}{ Monthly income from all sources (Rs.) } & \multicolumn{3}{|c|}{ Impact of youth empowerment on bringing social change } & \multirow{2}{*}{ Total } \\
\hline & Low & Medium & High & \\
\hline \multirow{2}{*}{ Up to 8000} & 7 & 14 & 11 & 32 \\
\hline & $21.9 \%$ & $43.8 \%$ & $34.4 \%$ & $100.0 \%$ \\
\hline \multirow{2}{*}{8000 to 16000} & 4 & 17 & 3 & 24 \\
\hline & $16.7 \%$ & $70.8 \%$ & $12.5 \%$ & $100.0 \%$ \\
\hline \multirow{2}{*}{16000 to 24000} & 12 & 10 & 11 & 33 \\
\hline & $36.4 \%$ & $30.3 \%$ & $33.3 \%$ & $100.0 \%$ \\
\hline \multirow{2}{*}{ Above 24000} & 18 & 56 & 37 & 111 \\
\hline & $16.2 \%$ & $50.5 \%$ & $33.3 \%$ & $100.0 \%$ \\
\hline \multirow{2}{*}{ Total } & 41 & 97 & 62 & 200 \\
\hline & $20.5 \%$ & $48.5 \%$ & $31.0 \%$ & $100.0 \%$ \\
\hline
\end{tabular}

Chi-square $=13.24$

d.f. $=6$ P-value $=.040^{\star \star}$ Gamma $=.107^{*}=$ Significant

Table 4 presents the association between monthly income from sources of the respondents and their perception about the impact of youth empowerment on bringing social change. Chi-square value shows a significant association between monthly income from sources of the respondents and their perception about the impact of youth empowerment on bringing social change. Gamma value shows a positive relationship between the variables. It means high income youth had more perception about the impact of youth empowerment on bringing social change as compared to low income. So the hypothesis "Higher the income of the respondents, higher will be the perception about the impact of youth empowerment on bringing social change" is accepted.

Hypothesis 5: Marital status of the youth will be influencing about their perception about the impact of youth empowerment on bringing social change 
Table 5: Association between marital status of the respondents and their perception about the impact of youth empowerment on bringing social change

\begin{tabular}{|c|c|c|c|c|}
\hline \multirow{2}{*}{ Marital status } & \multicolumn{2}{|c|}{ Impact of youth empowerment on bringing social change } & \multirow{2}{*}{ Total } \\
\cline { 2 - 5 } & Low & Medium & High & \\
\hline \multirow{2}{*}{ Single } & 11 & 59 & 50 & 120 \\
\cline { 2 - 5 } & $9.2 \%$ & $49.2 \%$ & $12 \%$ & $100.0 \%$ \\
\hline \multirow{2}{*}{ Married } & 30 & 38 & $15.0 \%$ & $100.0 \%$ \\
\cline { 2 - 5 } & $37.5 \%$ & $47.5 \%$ & 62 & 200 \\
\hline \multirow{2}{*}{ Total } & 41 & 97 & $31.0 \%$ & $100.0 \%$ \\
\cline { 2 - 5 } & $20.5 \%$ & $48.5 \%$ & & \\
\hline
\end{tabular}

Chi-square $=29.83$

d.f. $=2$ P-value $=.000^{* *}$ Gamma $=-.609$ ** $=$ Highly significant

Table 5 presents the association between marital status of the respondents and their perception about the impact of youth empowerment on bringing social change. Chi-square value shows a highly-significant association between marital status of the respondents and their perception about the impact of youth empowerment on bringing social change. Gamma value shows a negative relationship between the variables. It means unmarried youth had more perception about the impact of youth empowerment on bringing social change as compared to married youth. So the hypothesis "Marital status of the youth will be influencing about their perception about the impact of youth empowerment on bringing social change" is accepted.

\subsection{Regression Analysis}

Simple linear regression is applied to find out the relative importance of each and every independent variable in explaining the dependent variable i.e. satisfaction with decision to migrate. The value of regression co-efficient is use to establish the significance of independent variable in predicting response variable. The higher value of regression coefficient of variable is reflection of its higher importance in predicting the dependent variable. The value of $\mathrm{Co}$-efficient of variation $\left(R^{2}\right)$ is used to overall fitness of model.

Table 7: Results of Regression Analysis

\begin{tabular}{|l|c|c|c|c|c|}
\hline \multirow{2}{*}{ Variables } & \multicolumn{2}{|c|}{ Unstandardized Coefficients } & Standardized Coefficients & \multirow{2}{*}{ T Sig. } \\
\cline { 2 - 5 } & $\mathrm{B}$ & Std. Error & Beta & & \\
\hline (Constant) & 1.369 & .257 & & 5.319 & .000 \\
\hline Age & .0843 & .080 & .091 & 1.060 & .290 \\
\hline SEX & -.337 & .086 & .214 & -3.932 & .000 \\
\hline Education & .433 & .076 & .475 & 5.715 & .000 \\
\hline Income & .0074 & .033 & -.001 & -.023 & .982 \\
\hline Marital status & -.788 & .085 & -.544 & -9.314 & .000 \\
\hline Satisfaction with the policies regarding youth empowerment & .192 & .051 & .099 & 1.801 & .053 \\
\hline
\end{tabular}

Dependent Variable: Impact of youth empowerment on bringing social change, $\mathrm{R}^{2}=.49 \mathrm{~F}$-value $=31.36 \mathrm{Sig} .=.00^{\star *}$

The value of R-Square is 0.49 . This shows that the 49 percent change in youth empowerment on bringing social change was explained by four variables such as gender, education, marital status and satisfaction with the policies regarding women empowerment. The other two variables namely age of the respondent and income could not establish their importance in explaining the dependent variable. The overall significance of the model can also be judged by the F-test. The F-value is 31.36 which is significant at less than one percent level of significant. This too suggests that the model is highly significant.

\subsubsection{Impact of Age}

The coefficient for this variable had a positive sign with the value of 0.0843 and is non-significant at $5 \%$ level of significance. It shows the age has no impact on their perception about the impact of youth empowerment on bringing social changes. 


\subsubsection{Impact of sex}

The coefficient for education variable is 0.337 with a negative sign. This coefficient is statistically significant at $1 \%$ level of significance. It means female had more perception about the impact of youth empowerment on bringing social changes as compared to male.

\subsubsection{Impact of Education}

The coefficient for education variable is 4.33 with a positive sign. This coefficient is statistically significant at $1 \%$ level of significance. It shows education has positive impact on their perception about the impact of youth empowerment on bringing social changes. In other words respondents with higher level of education had more perception about the impact of youth empowerment on bringing social changes as compared to respondents with less educational attainment.

\subsubsection{Impact of income (after migration)}

The coefficient for this variable had a positive sign with the value of 0.0074 and is non-significant at $5 \%$ level of significance. It shows the income has no impact on their perception about the impact of youth empowerment on bringing social changes.

\subsubsection{Impact of marital status}

The coefficient for marital status variable is 0.778 with a negative sign. This coefficient is statistically significant at $1 \%$ level of significance. It means unmarried youth had more perception about the impact of youth empowerment on bringing social changes as compared to married youth.

\subsubsection{Impact of satisfaction with the policies regarding women empowerment}

The coefficient for satisfaction with the policies regarding women empowerment variable is 0.192 with a positive sign. This coefficient is statistically significant at $5 \%$ level of significance. It means if the respondents had more satisfaction with the policies regarding women empowerment then they also had more perception about the impact of youth empowerment on bringing social changes.

\subsubsection{Findings at bi-variate analysis}

A highly-significant association between gender and their perception about the impact of youth empowerment on bringing social change.

A highly-significant association between age of the respondents and their perception about the impact of youth empowerment on bringing social change.

\subsubsection{Findings at multivariate analysis}

The value of R-Square is 0.49 . This shows that the 49 percent change in youth empowerment on bringing social change was explained by four variables such as gender, education, marital status and satisfaction with the policies regarding women empowerment. The other two variables namely age of the respondent and income could not establish their importance in explaining the dependent variable. The overall significance of the model can also be judged by the F-test. The F-value is 31.36 which is significant at less than one percent level of significant. This too suggests that the model is highly significant.

\section{Conclusion}

Empowerment is essentially a liberty in political, economic, and social sector and having awareness on different issues especially on their rights. Youth participation is a process of involving young people in the institutions and decisions that affect their lives. As expressions of participation, young people are organizing groups for social and political action, 
planning programs of their own choosing, and advocating their interests in the community. They are raising consciousness, educating others on matters that concern them, and providing services of their own choosing. No single strategy characterizes all approaches to participation. Providing opportunities for youth to successfully participate in social change, giving them a voice, and be involved in civic affairs may develop a generation of youth who carry these skills into adulthood.

\section{References}

Mankoff, J., D. Matthews, S.R Fussel and M. Johnson. 2007. Leveraging social networks to motivate individuals to reduce their ecological footprints. Proceedings of the 40th Hawaii International Conference on System Sciences. DOI http://doi.ieeecomputersociety.org/10.1109/HICSS.2007.325

Marmot, M. 2005. Social determinants of health inequalities. Lancet, 365: 1099-1104.

Robert Kennedy, 2008. View this article at Wikipedia.org - Edit this article at Wikipedia.org - Donate to the Wikimedia Foundation

Who 2006. What is the evidence on effectiveness of empowerment to improve health? WHO Regional office for Europe's Health Evidence Network (HEN) Feb.2006. 